Research, part of a Special Feature on The Governance of Adaptation

\title{
A Governing Framework for Climate Change Adaptation in the Built Environment
}

\author{
Daniel A. Mazmanian ${ }^{1}, \underline{\text { John Jurewitz }}^{2}$ and Hal T. Nelson $^{3}$
}

\begin{abstract}
Developing an approach to governing adaptation to climate change is severely hampered by the dictatorship of the present when the needs of future generations are inadequately represented in current policy making. We posit this problem as a function of the attributes of adaptation policy making, including deep uncertainty and nonstationarity, where past observations are not reliable predictors of future outcomes. Our research links organizational decision-making attributes with adaptation decision making and identifies cases in which adaptation actions cause spillovers, free riding, and distributional impacts. We develop a governing framework for adaptation that we believe will enable policy, planning, and major long-term development decisions to be made appropriately at all levels of government in the face of the deep uncertainty and nonstationarity caused by climate change. Our framework requires that approval of projects with an expected life span of 30 years or more in the built environment include minimum building standards that integrate forecasted climate change impacts from the Intergovernmental Panel on Climate Change (IPCC) intermediate scenario. The intermediate IPCC scenario must be downscaled to include local or regional temperature, water availability, sea level rise, susceptibility to forest fires, and human habitation impacts to minimize climate-change risks to the built environment. The minimum standard is systematically updated every six years to facilitate learning by formal and informal organizations. As a minimum standard, the governance framework allows jurisdictions to take stronger actions to increase their climate resilience and thus maintain system flexibility.
\end{abstract}

Key Words: adaptive management; California; climate change adaptation; governance; planning

\section{INTRODUCTION}

A great deal of attention has been devoted to establishing a governing framework for mitigating greenhouse gas (GHG) emissions at the local, state, national, and international levels over the past decade. The three components of the mitigation framework include: (a) identification of the reasonably likely range of global warming associated with various levels of GHG emissions, based on the best available climate science, (b) recognition that addressing the problem requires substantial collective action, and (c) specification of a sciencebased policy goal for guiding this collective action. Where this framework has been adopted by public policy makers at the international, national, or subnational level of government, the commonly accepted goal is to reduce GHG emissions to a level that would keep global temperature from rising more than $2^{\circ}$ $\mathrm{C}$ by mid century and thus avoid the most catastrophic disruptions to human and natural systems. To date, the member states of the European Union, the two dozen states in the United States that have developed climate action plans, and the hundreds of city mayors around the world who have signed the Intergovernmental Council for Local Environmental Initiatives (http://www.icleiusa.org/climate and energy/ Climate_Adaptation_Guidance/climate-resilient-communitiesprogram) climate change pledge have accepted the $2^{\circ} \mathrm{C}$ objective as a guiding principle for action.

In this paper, we posit that climate change adaptation needs a governing framework analogous to the consensus framework that has evolved for mitigation. We define a governing framework as a decision support structure that guides public and private actions by providing (1) causal logic for policy actions, (2) policy goals, including minimum standards or policy targets, and (3) policy evaluation criteria. Like the consensus mitigation framework, our adaptation framework rests on climate science, identifies where collective action is needed, and prescribes an overarching policy goal. This framework should go well beyond providing information about vulnerabilities and their likely effects and mandating that public agencies anticipate climate change impacts in their strategic plans. This framework should provide a clear, overarching objective and path forward for guiding placebased adaptation measures at the national and subnational levels that are scientifically based, consistent, politically acceptable, and economically viable.

The theoretical work on adaptation governance guiding our research has expanded greatly in recent years. Biermann et al. (2010) elaborate on the analytical problems and research questions that need to be addressed. Pahl-Wostl (2009) addresses issues around definitions and theories of governance structures. The first element of our paper theorizes about how the attributes of adaptation decision making affect political and analytical decision processes. By doing so, we integrate decision sciences (Mun 2006, Dasgupta 2008) with existing theoretical work on climate policy and biases in decision making (Gowdy 2008, Lempert and Collins 2007). Our

${ }^{1}$ University of Southern California, ${ }^{2}$ Pomona College, ${ }^{3}$ Claremont Graduate University 
research adds a political dimension to the work of Smith et al. (2011) that links organizational decision making with adaptation decision making.

Our second contribution is to extend existing theoretical work on the governance of adaptation by identifying cases where adaptation actions cause spillovers, free riding, and distributional impacts. We build on Mazmanian et al. (2013), as well as on Tompkins and Eakin (2012), who make substantive contributions to the adaptation governance literature by delineating the nature of publicly provided versus privately provided goods for adaptation.

Finally, we help to operationalize adaptation governance by developing a minimum performance standard proposal for the built environment that adapts to the best available climate science. The minimum standard is systematically updated to facilitate learning by formal and informal organizations (PahlWostl 2009). As a minimum standard with updating, it also allows jurisdictions to take stronger actions to increase their climate resilience (Smith et al. 2011) and thus maintains system flexibility (Nelson et al. 2007). Our governing framework also requires global climate change models to be downscaled to evaluate regional impacts, thereby addressing the issue of scale appropriateness of adaptation actions discussed in Adger et al. (2005).

\section{METHODS: DECISION MAKING UNDER NONSTATIONARITY AND DEEP UNCERTAINTY}

In exploring why a governing framework for adaptation has yet to be adopted, we first identify two attributes of adaptation decision making that need to be considered in its design. These attributes include the death of stationarity in the biogeophysical sphere, and the deep uncertainty associated with climate change. The net effect of these two attributes is the subsequent reluctance by existing populations and their political leaders to address the needs of future generations. Deep uncertainty and nonstationarity increase the existing status-quo bias of political institutions by making adaptation benefit-cost analyses more problematic and by making delays in taking action, to obtain more and better information more acceptable.

\section{The death of stationarity}

In evaluating the cost/benefit ratio of projects in the built environment, it is conventional to project the investment life of the project for 30 to 100 years. In doing so, it has usually been assumed implicitly that the frequency distribution of past variations in the biogeophysical setting is a reasonably accurate guide to the range of likely future variations: e.g., historic records of the variations in future river flows, coastal tidal and storm event patterns, the location and frequency of major earthquakes, and the availability of arable land for agriculture. In the past, this operational assumption of stationarity has been sufficiently reliable to enable these investment and business decisions to be made with a reasonable degree of confidence in their physical durability and return on investment. To the extent that future land and biophysical configurations are going to be dramatically different because of the accelerating rate of climate change, relying on the stationarity of past patterns as a simplifying assumption in evaluating development proposals is extremely hazardous and ill-advised.

The fact of the death of stationarity is gradually becoming accepted in practice in some fields and has been evident in academia for a decade. At least with respect to water management, the long-standing and professionally codified assumption of stationarity is effectively dead. Milly et al. (2008:573) note, "In view of the magnitude and ubiquity of the hydroclimatic change apparently now under way ... we assert that stationarity is dead and should no longer serve as a central, default assumption in water-resource risk assessment and planning. Finding a suitable successor is crucial for human adaptation to changing climate."

Although the issue continues to be debated within professional circles (Huitema et al. 2009, Galloway 2011), nonstationarity is being incorporated into practice in the United States (Levin 2010, California Department of Transportation 2011, California Department of Water Resources 2011, U.S. Army Corps of Engineers 2011, U.S. Interagency Adaptation Task Force 2011). The death of stationarity has important implications that go well beyond the evaluation of development projects. Indeed, it calls into question the fundamental legal designation of real property. For example, as sea levels rise, even the constitutionally established dividing line between private and public property will shift and will create strong incentives to defend the status quo from this climate-driven "condemnation" process; for instance, in California this dividing line is the mean high tideline mark, and in Hawaii it is the line of coastal vegetation.

The death of stationarity brings with it enormous challenges. These include: (1) for climate scientists, projecting the pace of climate change and modeling the effects on natural resources and land masses at both the global and local level; (2) for engineers and architects, designing appropriate structures for the built environment; and (3) for decision makers, making responsible decisions about long-range projects and human activities. Hence, the death of stationarity will also have to be incorporated in developing a governing framework for adaptation.

\section{Deep uncertainty}

Relevant to governing adaptation, Robert Lempert and colleagues suggest that the projected effects of a host of social and biophysical processes are of a scale today unlike those previously experienced by any major society; they are the "wicked" problems of the 21 st century. Moreover, the risks accompanying the projected effects are sufficiently large and 
uncertain that conventional approaches for calculating them and for governing place-based decision making are inadequate. For climate change, models based on past patterns and events are inadequate for characterizing the effects of global warming and the complex biophysical dynamics that will result (Lempert et al. 2003, 2009, and Lempert and McKay 2011). This places us in an analytical environment of deep uncertainty, which Lempert defines as "a condition where the parties to a decision do not know or do not agree upon the system model relating potential actions to outcomes, the prior probabilities for the value of key uncertain input parameters to the system model(s), and/or the value function that should be used to rank alternative outcomes" (Lempert et al. 2009:115).

In this context of deep uncertainty, it is important for decision makers to avoid processes that in the past might have led to optimal or near-optimal outcomes, but which, if applied to cases of deep uncertainty, may lead to truly undesirable or even worst-case ones (Lempert and McKay 2011:2). Lempert does not provide a prescription for responding to the challenge, although he and Collins contend that whatever the decisionmaking process, it needs to be "robust;" it must "perform well over a wide range of plausible futures" (Lempert and Collins 2007:1016). In an environment of deep uncertainty, robust solutions may best be designed by approaching the objective as one of satisficing (satisfying plus sufficing) rather than optimizing.

In exploring how best to cope in this world of deep uncertainty, a host of less technically verifiable yet insightful methods are being developed. These range from simulations to narratives and Delphi and Foresight exercises (in which individuals and groups participate in imagining plausible scenarios about future states, based on alternative projections of climate change), to "no-regrets" strategies and the dynamic adaptive scenario approach being utilized today in water basin planning (Groves and Lempert 2007, Hallegatte 2009, and Haasnoot et al. 2013). All these approaches are intended to help policy makers better gauge what courses of action are preferable, in the light of the deep uncertainties they face (van Vuuren et al. 2011).

\section{Reluctance to act on behalf of the future}

The net effect of the nonstationarity and deep uncertainty is to enhance the tendencies of decision makers to procrastinate on implementing adaptation measures because of their lack of agreement, and to steeply discount the future costs of failing to adapt to climate change. These tendencies result in "the dictatorship of the present," in which future generations' needs are systematically ignored in current policies. This outcome is compounded by the very strong tendency of most environmental political theorists to focus on intragenerational equity and justice considerations to the exclusion of intergenerational considerations (Eckersley 1992). This has led to a serious deficiency in how to conceptualize governing adaptation (Adger et al. 2006). In view of the fact that current GHG emissions commit the world to higher levels of atmospheric GHG concentrations for an extended period of time, considerations of intergenerational equity are critical in making decisions about adaptation involving long-term development projects. Anticipating the impacts in the present and adjusting development to meet them will avoid imposing unnecessary pain and sacrifices on future generations (Stern 2006).

Human inconsistencies related to valuing the future are well known in welfare economics literature. These biases span a variety of decision subjects, including liquid assets (Laibson 1997), health expenditures (Chapman and Elstein 1995), and compound growth (Levy and Tasoff 2012). Regarding climate change, human temporal myopia can pose "deep difficulties ... for public policy" (Nordhaus 1999:145). We posit two mechanisms by which deep uncertainty and the death of stationarity impact the dictatorship of the present.

First, these two attributes enhance the natural tendency of political decision makers to avoid taking action on a potential problem of uncertain magnitude and timing, especially when some are skeptical that climate change will even happen. This tendency is especially pronounced when decision makers believe that there will be time to respond after they gain more information. This is akin to a real-options analysis, where, in situations of high uncertainty and long time horizons, there is significant embedded value in deferring investment until new information comes in (Mun 2006). However, the ability to defer investment assumes that there is adequate flexibility in meeting the policy or infrastructure project goals and that there will be adequate opportunity to make the investment later if it proves to be advisable. Rising sea levels and more extreme weather events will reduce the flexibility of jurisdictions to make adaptation investments over time.

The second mechanism by which deep uncertainty and nonstationarity increase the dictatorship of the present is by making the determination of benefits from adaptation measures more problematic. Consider the work of de Bruin et al. (2009), a recent adaptation inventory for the Netherlands, one of the most advanced countries with the greatest vulnerability to climate change. Table 4 (de Bruin et al. 2009:36) shows costs that are quantified, but benefits that are not. The cost side is potentially straightforward; adaptation measures for the built environment require upfront investment (at $\sim$ time $\mathrm{t}_{0}$ ) with a known cost of capital. Valuing the benefits of avoided damages in years $\mathrm{t}_{1}$-th is much more problematic and requires the choice of the term structure (step function) of the discount rate, as well as an estimate of damages from climate change. The result of deep uncertainty and nonstationarity is that adaptation benefits are not typically estimated because, de Bruin notes, "knowledge gaps exist, 
data are missing or their reliability is insufficient" (de Bruin et al. 2009:37).

Although scholars have called for methods other than expected utility to assess adaptation policies and measures (reviewed in Kuik et al. 2008), benefit-costs tests are still required for many public sector investments and regulatory impact assessments, and thus are our focus. We maintain that confidence in adaptation policy decision making is decreased by nonstationarity and deep uncertainty in two ways:

1. Nonstationarity and deep uncertainty raise questions about the appropriate initial value of the discount rate and its term structure. The debate about the choice of discount rates in climate policy is well known and has been covered adequately elsewhere (Stern 2006, Dasgupta 2008). Weitzman (2010) posits that the fear of lowprobability, high-impact events predicts long-term discounting preferences. Conceptually, increased uncertainty about system parameters, such as the probability of an extreme climate event, that results from deep uncertainty and nonstationarity can lead to hesitation to reduce risk-adjusted discount rates to zero or near-zero values.

2. The second decline in confidence in analytical methods comes from the increase in uncertainty about the choice of rates over time (Newell and Pizer 2003). Unless analytical methods are designed to capture uncertainty, the impacts on benefit valuation from the choice of an initial discount rate are potentially overshadowed by the effect of uncertainty. Consider two cases with a $\$ 1000$ initial investment over a 200 -year project life. Both have the same initial discount rate: Case 1 is in a more certain policy area with a consensus discount rate of $2 \%$. Case 2 is in an adaptation policy area with equal probabilities of $0 \%$ and $4 \%$, a mean of $2 \%$. The discounted benefits in Case 1 are $\$ 1000 * \exp ^{-0.02 * 200}=\sim \$ 18$. In Case 2 they are $0.5\left(\$ 1000 * \exp ^{-0.00 * 200}\right)+0.5\left(\$ 1000 * \exp ^{-0.04 * 200}\right)=$ $\sim \$ 500$, or over 27 times higher.

The uptake of weighting methodologies to reflect uncertainty, such as are described here and in Ben-Haim (2006), are likely to be hampered by conflict and lack of consensus over probability weightings that result from deep uncertainty and nonstationarity. Nor does more information necessarily mitigate these sources of uncertainty and therefore result in better agency decision making. Maynard (2006) posits that as data is collected, agencies have difficulty deciphering it. Jennings and Hall (2012) show that although American states' natural resource agencies score high on the use of professional/ scientific information, they also are not innovative and rely on political decision making, which can hamper the adoption of appropriate adaptation decision-making methodologies.

\section{RESULTS}

We maintain that governing institutions are inherently controlled by the present generation and cannot represent the interests of future generations, except to the extent that the present generation is both knowledgeable about the science and ethically empathetic toward the future. Under the public trust doctrine, governments have the responsibility for managing and conserving natural resources and habitats for posterity. However, precisely what this means in practice is open to interpretation by the current generation. The challenge, therefore, is to develop a governing framework for adaptation that provides for the needs of the present while taking into account those of future generations. Although we do not completely resolve this problem, our proposal provides a major step in this direction.

Because the built environment has been traditionally governed locally, especially where property rights are held privately, it is understandable that higher-level policy makers are reluctant to adopt a comprehensive governing framework for adaptation. To date only a relatively few nonprofit organizations and governing bodies have adopted one or more informational, educational, planning and adaptation activities (Berkhout 2006, California Resources Agency 2009, Levin 2010, Agrawala et al. 2011; Local Governments for Sustainability [ICLEI], http://www.iclei.org). As climate change progresses, however, the number of situations calling for collective action will grow in number, as will the pressure on policy makers to respond.

An appropriate adaptation framework should be based on the same logic as an appropriate mitigation framework. Specifically, it must be scientifically based, as opposed to being based on personal preferences, economic interests, or culture. It must cover the gamut of collective action challenges, like those we are presently considering, those posed to the built environment precipitated by global warming. The policy actions involved must be sufficiently clear and pragmatic to enable decision making on the ground to go forward. As argued by Lempert and Collins (2007) and Lempert et al. (2009), the governing framework must be robust, i.e., reasonably effective over a wide range of possible futures. In effect, a high-level, widely applicable goal is needed to govern collective action decisions affecting the built environment in myriad placespecific, decentralized development decisions.

\section{Collective action attributes of adaptation for the built environment}

There is growing appreciation of the fundamental differences in the public policies needed to curtail GHG emissions versus those needed to adapt to the effects of global warming (Adger et al. 2005, IPCC 2011). The most widely recognized difference is that mitigation requires collective action among the preponderance of GHG-emitting nations (Young 2009), but that a great many adaptation measures, by their very nature, 
often can be adequately addressed individually, selectively, and can be based on the local capacity to respond, without the need for elaborate coordination and cooperation (Adger 2003, Zahran et al. 2008). This is because GHG emissions are a public bad and GHG mitigation is, therefore, a public good, subject to free riding and requiring the reduction of GHGs across millions and millions of emitters, spread throughout the nations of the world.

Compared to mitigation, the rationale for supporting collective public action in adaptation is not as categorical. Every place and everyone will not be affected by the "public bads" effects of climate change in the same way, nor will any particular adaptation response be universally appropriate. Some adaptation activities can be satisfactorily undertaken by individuals or groups voluntarily acting on their own initiative. However, to be sure, others will be best carried out collectively, requiring coordinated action among some broader group of people. Moreover, even in instances in which individual responses are technically feasible and can be expected, such as in building a seawall to protect one's beachfront property, the potential externalities and spillover effects may require a more collective public policy approach.

Our work builds on that of Tompkins and Eakin (2012), which identifies many adaptation measures that may and should be private. There are several general situations, however, under which private and collective adaptation actions will require a governing framework (Mazmanian et al. 2013). We identify three such situations:

1. Private or collective adaptation decisions involving significant spillovers or free-riding: For instance, individuals might be inclined to take adaptive steps that make perfectly good private sense and would afford them an increment of protection from the effects of climate change, but would increase damages or adaptation costs incurred by others. In general, two types of public policy rules fall within this category. The first type includes rules that constrain individuals from doing things that serve their own interests but have adverse spillover effects on others. The second category contains rules that require individuals to undertake some action, or undertake it to a greater degree than they would freely choose, because of positive spillover effects on others. For instance, local zoning and land-use regulations typically regulate behavior with positive and negative spillovers. For an example of positive externalities, consider the Flood Prevention Action Plans in France, described by Erdlenbruch et al. (2009), where rural landowners are incentivized to modify their embankments or vegetation to increase floodwater storage, to reduce downstream urban flood risks.

2. Adaptive steps involving significant scale economies or coordination economies: Certain adaptation projects may be of such large magnitude or geographic scale that it strains credulity to think that they will be provided by the private sector on an efficient and equitable basis. This category of adaptive policies includes extensive seawalls and large water projects. In some cases, e.g., water projects, existing institutions are already active in these policy areas and the challenge is to have these institutions approach their adaptation planning on a coordinated and mutually consistent basis. In other cases, e.g., seawalls, there may be no existing public institutions, and the challenge will be to create them and coordinate their responsibilities with existing related institutions.

3. Adaptive steps with significant distributional implications: In some cases, undertaking necessary adaptation measures may involve serious issues of income distribution or social justice. In these cases, public sector funding may be warranted, even for those categories of actions that would otherwise be adequately addressed through purely private decision making. Although many of these cases will involve purely intranational politics and decision making, other obvious and well-publicized problems will necessitate international cooperation and action. For instance, highly vulnerable low-lying countries and islands, e.g., the Alliance of Small Island States, may be severely impacted or even wiped off the face of the map. At a minimum, the international community should act cooperatively to adopt international public policies to share the burden of providing aid and relocation to these populations.

Successful adaptation planning and enactment will encompass many public and club goods that include significant positive and negative externalities. This category of adaptive policies includes extensive seawalls and large water projects. Seawalls are an example of a club good whose benefits are received by a select group of firms or individuals who can exclude others from their use. Therefore, the scale and level of the adaptation measures implemented must match the scale and level of authority in decision-making processes.

\section{Establishing the goal in governing adaptation for the built environment}

Given these collective-action considerations, we next posit that a numerical goal for adaptation is required, akin to the $2^{\circ}$ $\mathrm{C}$ by 2050 goal for mitigation adopted by the Intergovernmental Panel on Climate Change (IPCC 2007). The IPCC target for mitigation has been widely accepted as an aspirational goal by all the national and subnational governing bodies that have enacted mitigation policies. Climate change forecasts are presented as a set of scenarios, ranging from a high level of global warming based on "business as usual" to a very optimistic reduction of the anthropogenic release of GHG emissions. Nonetheless, in the face of these multiple scenarios, the $2^{\circ} \mathrm{C}$ target serves as a common GHG mitigation goal around the world. 
A comparably robust policy goal is needed to guide adaptation policies. As with mitigation, there must be a widely recognized scientific body responsible for projecting coming changes; there must be national and subnational governments prepared to acknowledge the level of threats they are facing; and there must be robust and continuously revisited criteria for development to proceed in the face of those threats. Our framework requires that for any project with an expected life span of 30 years or more, its approval must take into account the best scientific estimates of global warming effects, such as changes in local temperature, water availability, sea level rise, susceptibility to forest fires, and human habitability in general. The 30-year time horizon requires anticipating future effects and adopting a realistic time frame for building and investment decisions.

\section{The role of climate change science}

The impacts of climate change need to be estimated at the subnational level, to have adequate adaptation planning (Hunt and Watkiss 2011). To ascertain the best estimates of global warming projections, we identify two linked sources. The first is the work of the IPCC, used as a point of departure. For the past quarter century, it has provided the best scientifically determined range of potential futures, which can serve as the foundation for adaptation planning. The IPCC reports are the result of scientific consensus, recognized worldwide, and the organization has demonstrated staying power. In governing the built environment, two other factors are required. When it comes to development decisions in the built environment, it is beneficial to have a single set of scenario projections upon which to base decisions, rather than leaving this matter to the discretion of local developers and decision makers.

For this purpose, we recommend adopting the IPCC's intermediate scenario as the base-case scenario for downscaled impact modeling, along with somewhat higher and lower scenarios to form the basis of sensitivity analyses to test the robustness of policies. An appropriate intermediate IPCC scenario could be defined as approximating the midpoint between the business-as-usual energy and population growth scenario, at one end, and successful energy technology development at the other end of the IPCC range. For example, the middle-range IPCC B2 and A1T scenarios in their 2007 report (IPCC 2007) are likely approximately appropriate intermediate scenarios. Sensitivity analysis around the intermediate scenario could serve to specify the operational assumptions and adaptation design parameters used by authorizing and permitting agencies in all situations where collective adaptive action is needed. In light of deep uncertainty and nonstationarity, decisions about the built environment need to be reviewed and updated as new IPCC intermediate forecasts become available. This approach conforms to adaptive management practices as learning principles that are emerging in water resource management (Huntjens et al. 2012).
Second, the framework element begins to address the scale issues that plague adaptation responses (Adger et al. 2005). The IPCC intermediate forecast will need to be downscaled to the governing jurisdictions and specific sites where projects are proposed. For example, if the intermediate scenario forecasts a sea-level rise of $1 \mathrm{~m}$ by 2050 along the coastline of the Netherlands because of coastal land subsidence and higher sea levels, any major public or private development with a life span of 30 years or more proposed along the coast would need to demonstrate that it could withstand a $2 \mathrm{~m}$ sea rise at a minimum, or would need to accept the responsibility and liability for failing to do so. If the intermediate scenario forecasts a sea rise of $0.5 \mathrm{~m}$ along the west coast of the United States, projects would need to demonstrate the same things as the Netherlands project, but at the lesser level.

The legal issues surrounding government liability for climate change adaptation are beyond the scope of this paper, but are covered elsewhere (Farber 2007, Faure and Peeters 2011). State and local governments that adopt and implement the minimum standard would not necessarily be immune to civil negligence suits for sea level rise or storm surges, but the standard would demonstrate that jurisdictions exercise reasonable care in protecting property and human safety. In some countries, legislatures have adopted statutes that limit local governments' liability for negligence (England 2007).

\section{DISCUSSION}

There are several legal implications that accompany the governance standard. The framework assumes that the intermediate level of IPCC scenarios represents the best assessment, scientifically speaking, available at the time of a decision. Importantly, once this minimum standard is set, approving agencies would not be able to deny a proposed development based on the failure to meet a projection of more extreme effects, such as a 2-meter sea-level rise along the west coast of the United States. In terms of legal and financial liability, those approving an action and those responsible for building adaptively within the parameters of the intermediate scenario would not be held liable if, during the 30-year life of the project, the effects of climate change turned out to be more or less severe. Conversely, the approving entity and project developers would be liable for damages from climate change effects during the 30-year period, if they were to approve and develop to a lesser standard of threat protection than indicated necessary by the IPCC intermediate scenario. In essence, the intermediate IPCC scenario would be the lines painted in the road; they do not themselves prevent accidents, but they help sort out the respective liabilities after the fact and thereby establish appropriate incentives for exercising due care.

From today's perspective, it seems doubtful that a uniform governing framework for adaptation will be formally adopted worldwide. A well-known fact about policy making is that agreement on the nature and severity of a collective problem, 
even when combined with the most persuasive arguments, does not assure an effective policy response. For example, climate change has not been a high priority policy area for many state agencies in the United States (Brody et al. 2010). What will it take for this to change? Despite the strong consensus among climate scientists and the growing acceptance among policy makers of the reality of climate change, adoption of a governing framework for adaptation will depend a good deal on political will: the timing and political entrepreneurship that aligns the problem, the policy proposal, and the political opportunities of the issue (Kingdon 2010). Although there may be some debate about the degree of shared consensus regarding the need for coordinated adaptation policy, there seems to be little question that the political will to act is absent, at least at the moment.

The field of policy analysis also suggests that political leaders may gradually come to see the necessity of acting as climate change impacts become more and more evident, and as individuals start taking actions into their own hands, with adverse collective consequences. More likely, however, theoretical arguments presented here, including nonstationarity, deep uncertainty, and the accompanying dictatorship of the present imply that it will take multiple major shocks to the system before the time becomes ripe for a strong governing framework to be adopted at the national and subnational levels. These shocks include a sequence of extreme weather events or rapid changes in temperature that result in fundamental changes in weather patterns, droughts, forest fires, heat waves, and coastline destruction. The ability of a single extreme weather event to change (re)development patterns is proving doubtful (Anderson 2013). If the pace of mitigation does not accelerate rapidly and the more extreme projections of global warming begin to unfold (Peters et al. 2013), the need for adoption of a framework for adaptation may come sooner than currently imagined. Fortunately, the need to do so is nowhere near as important as with the worldwide cooperative adoption of mitigation policies. The challenges in adaptation and the need for collective action in the built environment are evolving more gradually and, in most part, in a more locally focused manner. Although the proposed adaptation framework can be a model for worldwide adoption, its adoption by nations and subnational governing bodies can be piecemeal, depending on the nature of the projected global warming impacts.

Although the scientific community has confidence in the IPCC's projections, it is doubtful that any major nation today will be inclined to legally bind itself to automatically take specific action exclusively based on the IPCC's analysis and recommendations. Among other things, the inputs and methodologies used to develop the IPCC scenarios are well beyond the control of the government of any nation. However, it is imaginable that national and subnational leaders will call for their own climate change assessments and will require their own monitoring entities to update and revise their adaptation guidelines, independently of, but scientifically in keeping with, IPCC modeling. To be useful in guiding the built environment, climate change scenarios will need to be downscaled to the regional, community, and even site-specific level (Sleeter et al. 2012), as exemplified by the 2-kilometer resolution climate change model being developed for the Los Angeles region by Hall et al. (2012).

The need for a governing framework, including a minimum standard for the development of the built environment, may seem self-evident to many, although it may strike others as just another example of encroaching government. The latter concern needs to be acknowledged. At the core of the issue is whether the benefits of a coordinated public response exceed the benefits of decentralized and diversified individual responses. In some situations, a laissez-faire approach to adaptation, in which stakeholders simply protect themselves, may be appropriate if (1) there are no interdependencies among the adaptation actions of individuals, (2) there are no economies of scale in collective action, (3) there are no intergenerational impacts to be protected by the public trust, and (4) there are no strong wealth distributional impacts that need to be addressed through national policies or international treaties. However, many situations fail this test and call for a public policy to guide adaptation.

From a governance perspective, the implementation of an adaptation governance standard will require significant political capacity and political will. The implementation of complex policies to protect the environment requires technical expertise and financial resources (Nelson 2012). These resources are distributed unevenly across subnational jurisdictions even in the developed world, to say nothing of the situation among developing countries. The forecasting of downscaled climate change impacts will be a significant hurdle for many jurisdictions and will likely require substantial analytical capacity building.

\section{CONCLUSION}

We argue that adaptation to climate change is in need of a governing framework analogous to that in existence today for mitigation. We developed a governing framework that is applicable to the built environment, a large arena, although not the singular arena where adaptation is required in response to the real and projected effects of climate change. The framework calls for the approval of projects with an expected life span of 30 years or more in the built environment to include minimum building standards that integrate forecasted climate change impacts from the IPCC intermediate scenario or the equivalent. In order to make local decisions, the scenarios will need to be downscaled to be contextually relevant to local or regional temperature, water availability, sea level rise, susceptibility to forest fires, and human habitation impacts. Reflecting the latest scientific understanding of climate change impacts in the periodically updated IPCC scenarios, 
building standards will need to be updated approximately every six years to facilitate learning by formal and informal organizations. As a minimum standard, this governance framework will allow jurisdictions to take actions and continue to evolve in a manner that increases their climate resilience, while maintaining flexibility in moving forward. Although the imminent adoption of such a generally applied framework does not seem likely in view of the present political climate and resistance to imposing a new and universal requirement for the built environment, it may come to pass sooner than most can imagine today.

Responses to this article can be read online at: http://www.ecologyandsociety.org/issues/responses. php/5976

\section{LITERATURE CITED}

Adger, W. N. 2003. Social capital, collective action, and adaptation to climate change. Economic Geography 79:387-404.

Adger, W. N., N. W. Arnell, and E. L. Tompkins. 2005. Successful adaptation to climate change across scales. Global Environmental Change 15:77-86. http://dx.doi.org/10.1016/j. gloenvcha.2004.12.005

Adger, W. N., J. Paavola, S. Hug, and M. J. Mace. 2006. Fairness in adaptation to climate change. MIT Press, Cambridge, Massachusetts, USA.

Agrawala, S., M. Carraro, N. Kingsmill, E. Lanzi, M. Mullan, G. Prudent-Richard. 2011. Private sector engagement in adaptation to climate change: approaches to managing climate risks. OECD Environment Working Papers, No. 39, OECD Publishing, Paris, France. http://dx.doi. org/10.1787/5kg221jkf1g7-en

Anderson, J. 2013. Rebuilding the local zoning and land-use regulations, but at what cost? New York Times. May 18.

Ben-Haim, Y. 2006. Info-gap decision theory: decisions under severe uncertainty. Academic (Elsevier), Oxford, UK, and Amsterdam, Netherlands.

Berkhout, F., J. Hertin, and D. M. Gann. 2006. Learning to adapt: organisational adaptation to climate change impacts. Climatic Change 78:135-156. http://dx.doi.org/10.1007/ s10584-006-9089-3

Biermann, F., M. M. Betsill, J. Gupta, N. Kanie, L. Lebel, D. Liverman, H. Schroeder, B. Siebenhüner, and R. Zondervan. 2010. Earth system governance: a research framework. International Environmental Agreements: Politics, Law and
Economics 10(4):277-298. http://dx.doi.org/10.1007/ s10784-010-9137-3

Brody, S., H. Grover, E. Lindquist, and A. Vedlitz. 2010. Examining climate change mitigation and adaptation behaviours among public sector organisations in the USA. Local Environment: The International Journal of Justice and Sustainability 15(6):591-603. http://dx.doi.org/10.1080/135$\underline{49839.2010 .490828}$

California Department of Transportation. 2011. Guidance on incorporating sea level rise. Prepared by the Caltrans Climate Change Workgroup and HQ Divisions of Transportation Planning, Design, and Environmental Analysis. [online] URL: http://www.dot.ca.gov/ser/downloads/sealevel/guide incorp slr. pdf

California Department of Water Resources. 2011. Climate change handbook for regional water planning. Developed by the California Department of Water Resources, U.S. Environmental Protection Agency, Resources Legacy Fund, and the U.S. Army Corps of Engineers. California Department of Water Resources, Sacramento, California. [online] URL: http://www.water.ca.gov/climatechange/CCHandbook.cfm

California Resources Agency. 2009. Climate adaptation strategy: a report to the governor of the State of California in response to Executive Order S-13-2008. California Natural Resources Agency, Sacramento, California, USA. [online] URL: www.climatechange.ca.gov/adaptation/

Chapman, G. B., and A. S. Elstein. 1995. Valuing the future: temporal discounting of health and money. Medical Decision Making 15(4):373-386. http://dx.doi.org/10.1177/0272989X$\underline{9501500408}$

Dasgupta, P. 2008. Discounting climate change. Journal of Risk and Uncertainty 37(2-3):141-169. http://dx.doi. org/10.1007/s11166-008-9049-6

De Bruin, K., R. B. Dellink, A. Ruijs, L. Bolwidt, M. W. van Buuren, J. Graveland, R. S. de Groot, P. J. Kuikman, S. Reinhard, R. P. Roetter, V. C. Tassone, A. Verhagen, and E. C. van Ierland. 2009. Adapting to climate change in the Netherlands: an inventory of climate adaptation options and ranking of alternatives. Climatic Change 95(1-2):23-45. http://dx.doi.org/10.1007/s10584-009-9576-4

Eckersley, R. 1992. Environmentalism and political theory: toward an ecocentric approach. State University of New York Press, Albany, New York, USA.

England, P. 2007. Climate change: what are local governments liable for? Urban Research Program Issues Paper 6. Griffith University, Brisbane, Australia. [online] URL: http://www. griffith.edu.au/_data/assets/pdf_file/0011/48566/urp-ip06england-2007.pdf 
Erdlenbruch, K., S. Thoyer, F. Grelot, R. Kast, and G. Enjolras. 2009. Risk-sharing policies in the context of the French Flood Prevention Action Programmes. Journal of Environmental Management 91(2):363-369. http://dx.doi.org/10.1016/j. jenvman.2009.09.002

Farber, D. A. 2007. Adapting to climate change: who should pay? Journal of Land Use \& Environmental Law 23:1-36.

Faure, M. G., and M. Peeters, editors. 2011. Climate change liability. Edward Elgar, Cheltenham, UK. http://dx.doi. org/10.4337/9781849806022

Galloway, G. E. 2011. If stationary is dead, what do we do now? Journal of the American Water Resources Association 47:563-570. http://dx.doi.org/10.1111/j.1752-1688.2011.00550. $\underline{\mathrm{x}}$

Gowdy, J. M. 2008. Behavioral economics and climate change policy. Journal of Economic Behavior \& Organization 68 (3-4):632-644. http://dx.doi.org/10.1016/j.jebo.2008.06.011

Groves, D. G., and R. J. Lempert. 2007. A new analytic method for finding policy-relevant scenarios. Global Environmental Change 17:73-85. http://dx.doi.org/10.1016/j.gloenvcha.2006.11.006

Hall, A., F. Sun, D. Walton, S. Capps, X. Qu, H.-Y. Huang, N. Berg, A. Jousse, M. Schwartz, M. Nakamura, R. CerezoMota. 2012. Mid-century warming in the Los Angeles Region: Part I of the "Climate change in the Los Angeles region project." [online] URL: http://c-change.la/pdf/LARC-web. pdf

Hallegatte, S. 2009. Strategies to adapt to an uncertain climate change. Global Environmental Change 19:240-247. http://dx. doi.org/10.1016/j.gloenvcha.2008.12.003

Haasnoot, M., J. H. Kwakkel, W. E. Walker, and J. ter Maat. 2013. Dynamic adaptive policy pathways: a method for crafting robust decisions for a deeply uncertain world. Global Environmental Change 23:485-498. http://dx.doi.org/10.1016/ j.gloenvcha.2012.12.006

Huitema, D., E. Mostert, W. Egas, S. Moellenkamp, C. PahlWostl, and R. Yalcin. 2009. Adaptative water governance: assessing the institutional prescriptions of adaptive (co-) management from a governance perspective and defining a research agenda. Ecology and Society 14(1): 26. http://www. ecologyandsociety.org/vol14/iss1/art26/

Hunt, A., and P. Watkiss. 2011. Climate change impacts and adaptation in cities: a review of the literature. Climatic Change 104(1):13-49. http://dx.doi.org/10.1007/s10584-010-9975-6

Huntjens, P., L. Lebel, C. Pahl-Wostl, J. Camkin, R. Schulze, and N. Kranz. 2012. Institutional design propositions for the governance of adaptation to climate change in the water sector. Global Environmental Change 22:67-81. http://dx.doi. org/10.1016/j.gloenvcha.2011.09.015
Intergovernmental Panel on Climate Change (IPCC). 2007. Climate Change 2007: sythesis report. R. K. Pachauri and A. Reisinger, editors .Contribution of Working Groups I, II and III to the Fourth Assessment Report of the Intergovernmental Panel on Climate Change. IPCC, Geneva, Switzerland. [online] URL: http://www.ipcc.ch/publications and data/ publications_ipcc_fourth_assessment_report_synthesis_report. $\underline{\mathrm{htm}}$

Intergovernmental Panel on Climate Change (IPCC). 2011. Managing the risk of extreme events and disasters to advance climate change adaptation: summary for policymakers: [online] URL: http://ipcc-wg2.gov/SREX/images/uploads/ SREX-SPM_FINAL.pdf

Jennings, E. T., and J. L. Hall. 2012. Evidence-based practice and the use of information in state agency decision making. Journal of Public Administration Research and Theory 22 (2):245-266. http://dx.doi.org/10.1093/jopart/mur040

Kingdon, J. 2010. Agendas, alternatives, and public policies. Second edition, updated, with an epilogue on health care. Pearson, New York, New York, U.S.A.

Kuik, O., B. Buchner, M. Catenacci, A. Goria, E. Karakaya, and R. Tol. 2008. Methodological aspects of recent climate change damage cost studies. Integrated Assessment 8 (1):19-40.

Laibson, D. 1997. Golden eggs and hyperbolic discounting. Quarterly Journal of Economics 112(2):443-478. http://dx. doi.org/10.1162/003355397555253

Lempert, R. J., and M. T. Collins. 2007. Managing the risk of uncertain threshold responses: comparison of robust, optimum, and precautionary approaches. Risk Analysis 27:1009-1026. http://dx.doi.org/10.1111/j.1539-6924.2007.00940. $\underline{\mathrm{x}}$

Lempert, R., and S. McKay. 2011. Some thoughts on the role of robust control theory in climate-related decision support. Climatic Change:107(3-4):241-246. http://dx.doi.org/10.1007/ s10584-011-0135-4

Lempert, R. J., S. Popper, and S. Banks. 2003. Shaping the next one-hundred years: new methods for quantitative, longterm policy analysis. RAND Corporation, Santa Monica, California, USA.

Lempert, R. J., J. Scheffran, and D. Sprinz. 2009. Methods for long-term environmental policy challenges. Global Environmental Politics 9:106-133. http://dx.doi.org/10.1162/ glep.2009.9.3.106

Levin, K. 2010. World resources 2010 framing paper: decision making in a changing climate. World Resources Report, Washington D.C., USA [online] URL: http://www.wri.org/ sites/default/files/uploads/wrr framing paper.pdf 
Levy, M. R., and J. Tasoff. 2012. Exponential-growth bias and lifecycle consumption. Social Science Research Network. http://dx.doi.org/10.2139/ssrn.2144358

Maynard, R. A. 2006. Presidential address: evidence-based decision making: What will it take for decision makers to care? Journal of Policy Analysis and Management 25:249-65. http:// dx.doi.org/10.1002/pam.20169

Mazmanian, D., J. Jurewitz, and H. Nelson. 2013. The paradox of "acting globally while thinking locally": discordance in climate change adaptation policy formation. Journal of Environment and Development 22(1):1-21.

Milly, P. C. D., J. Betancourt, M. Falkenmark, R. M. Hirsch, A. W. Kundzewicz, D. P. Lettenmaier, and R. J. Stouffer. 2008. Stationarity is dead: whither water management? Science 319:573-74. http://dx.doi.org/10.1126/science.1151915

Mun, J. 2006. Real options analysis: tools and techniques for valuing strategic investments and decisions. Wiley, Hoboken, New Jersey, USA.

Nelson, H. T. 2012. Government performance and U.S. residential building energy codes. Pages 267-292 in J. Kugler and R. L. Tammen, editors. The performance of nations. Rowman \& Littlefield, Lanham, Maryland, USA, and Plymouth, UK.

Nelson, D. R., W. N. Adger, and K. Brown. 2007. Adaptation to environmental change: contributions of a resilience framework. Annual Review of Environment and Resources 32:395-419. http://dx.doi.org/10.1146/annurev. energy.32.051807.090348

Newell, R. G., and W. A. Pizer. 2003. Discounting the distant future: how much do uncertain rates increase valuations? Journal of Environmental Economics and Management 46 (1):52-71. http://dx.doi.org/10.1016/S0095-0696(02)00031-1

Nordhaus, W. D. 1999. Discounting and public policies that affect the distant future. Pages 145-162 in P. Portney and J. Weyant, editors. Discounting and intergenerational equity. Resources for the Future Press, Washington, D.C., USA.

Pahl-Wostl, C. 2009. A conceptual framework for analysing adaptive capacity and multi-level learning processes in resource governance regimes. Global Environmental Change 19(3):354-365. http://dx.doi.org/10.1016/j.gloenvcha.2009.06.001

Peters, G. P, R. M. Andrew, T. Boden, J. G. Canadell, P. Ciais, C. Le Quéré, G. Marland, M. R. Raupach, and C. Wilson. 2013. The challenge to keep global warming below $2^{\circ} \mathrm{C}$. Nature Climate Change 3:4-6. http://dx.doi.org/10.1038/ $\underline{\text { nclimate } 1783}$

Sleeter, B. M., T. L. Sohl, M. A. Bouchard, R. R. Reker, C. E. Soulard, W. Acevedo, G. E. Griffith, R. R. Sleeter, R. F. Auch, K. L. Sayler, S. Prisley, and Z. Zhu. 2012. Scenarios of land use and land cover change in the coterminous United States: utilizing the special report on emission scenarios at ecoregional scales. Global Environmental Change 22 (4):896-914. http://dx.doi.org/10.1016/j.gloenvcha.2012.03.008

Smith, M. S., L. Horrocks, A. Harvey, and C. Hamilton. 2011. Rethinking adaptation for a $4^{\circ} \mathrm{C}$ world. Philosophical Transactions of the Royal Society A: Mathematical, Physical and Engineering Sciences 369 (1934):196-216. http://dx.doi. org/10.1098/rsta.2010.0277

Stern, N. 2006. The economics of climate change. Cambridge University Press, Cambridge, UK.

Tompkins, E. L., and H. Eakin. 2012. Managing private and public adaptation to climate change. Global Environmental Change 22:3-11. http://dx.doi.org/10.1016/j.gloenvcha.2011.09.010

U. S. Army Corps of Engineers. 2011. Sea-level change considerations for civil works programs. Circular 1165-2-212. U. S. Army Corps of Engineers, Department of the Army, Washington, D.C.

U. S. Interagency Climate Change Adaptation Task Force. 2011. Federal actions for a climate resilient nation. U.S. Interagency Climate Change Adaptation Task Force Progress Report, Washington D.C., USA.

van Vuuren, D. P., M. Isaac, Z. W. Kundzewicz, N. Arnell, T. Barker, P. Criqui, F. Berkhout, H. Hilderink, J. Hinkel, A. Hof, A. Kitous, T. Kram, R. Mechler, and S. Scrieciu. 2011. The use of scenarios as the basis for combined assessment of climate change mitigation and adaptation. Global Environmental Change 21:575-591. http://dx.doi.org/10.1016/ j.gloenvcha.2010.11.003

Young, O. R. 2009. Governance for sustainable development in a world of rising independence. Pages 12-40 in M. A. Delmas and O. R. Young, editors. Governance for the environment: new perspectives. Cambridge University Press, Cambridge, UK. http://dx.doi.org/10.1017/CBO9780511627170.003

Weitzman, M. L. 2010. Risk-adjusted gamma discounting. Journal of Environmental Economics and Management 60 (1):1-13. http://dx.doi.org/10.1016/j.jeem.2010.03.002

Zahran, S., S. D. Brody, A. Vedlitz, H. Grover, and C. Miller. 2008. Vulnerability and capacity: explaining local commitment to climate change policy. Environment and Planning C: Government and Policy 26:544-562. http://dx. doi.org/10.1068/c2g 